\title{
Identification of loads of the construction of a Hybrid Multimedia Mobile Stage
}

\author{
Michat Liss ${ }^{1,}{ }^{*}$, Tomasz Kałaczyński ${ }^{1}$, Natalia Dluhunovych ${ }^{2}$, Aleksandr Dykha $^{2}$ and Ronald \\ M. M artinod ${ }^{3}$ \\ ${ }^{1}$ University of Science and Technology, Faculty of M echanical Engineering, A I. prof. S. Kaliskiego 7 \\ 85-789 Bydgoszcz, Poland \\ ${ }^{2} \mathrm{~K}$ hmel nytsky N ational U niversity, 29016, 11, Instytutska Street, K hmelnitsky, U kraine \\ ${ }^{3}$ EA FIT U niversity, Facoulty of M echanical Engineering, Carrera 49 N 7 sur 50, Colombia
}

\begin{abstract}
The construction of the mobile stage is a huge challenge for designers due to a very wide range of variable factors affecting it, such as wind or temperature, the value of which in this case depends on the geographical location. A $n$ inherent element of the influence of these factors are the accompanying various, both constant and variable loads. Detailed identification of these loads is extremely important both for the safety of use and the diagnostic possibilities of such a complex mechanical structure.
\end{abstract}

\section{Introduction}

The mobile stage is usually a bar structure, the main components of which are reduced to beams and columns shaped as trusses, flat or spatial frames. The analyzed hybrid multimedia mobile scene consists of two important groups of structural el ements in relation to which the identification of loads affecting the structure will be made. The analyzed concept of a hybrid multimedia mobile scene structure is shown in Figure 1.

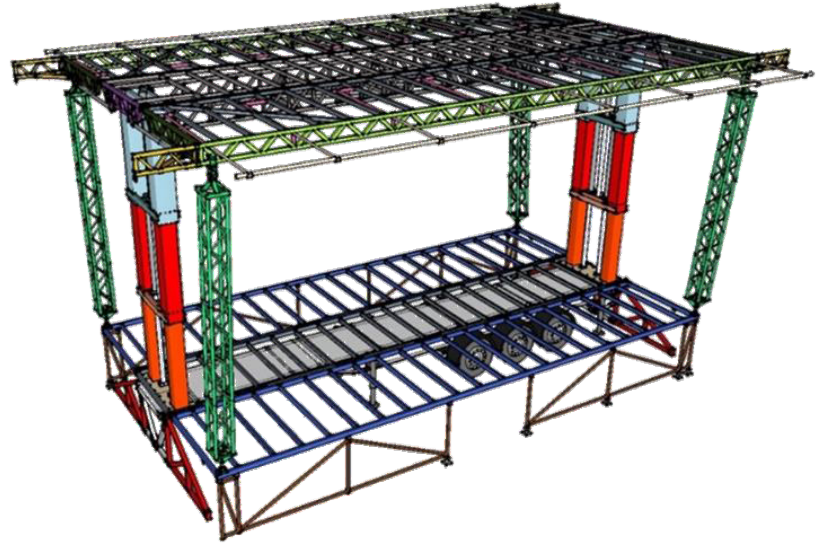

Fig. 1. Hybrid M ultimedia M obile Stage - I design concept - in the unfolded state.

The first group consists of beams bearing bar features, with a full-walled cross-section, usually loaded transversely to their longitudinal axis. The occurrence of axial forces in this type of elements does not significantly affect its ultimate strength. In some parts of the scene structure, the resultant of the beam $\odot$ transverse forces may pass beyond the shear center of the cross-section, causing the element to twist.

A nother group consists of structural elements in the form of built-up columns, whose particular task is to transfer compressive loads, e.g. resulting from the existing longitudinal

* Corresponding author: michal.liss@utp.edu.pl 
forces. In the analyzed concept of the construction of the hybrid mobile stage, the poles will be supported by a bar roof structure, and in addition, a multimedia screen, lighting and other audio-video equipment will be attached to them. The columns can be loaded axially or eccentrically, axially and transversely (bending), and axially bending and torsionally.

The mentioned two important groups of construction elements of the mobile stage will therefore form a bar (skeleton) system understood as a set of directly connected construction elements designed to transfer multidirectional internal and external loads.

In the light of Polish law, the mobile scene is treated as a temporary construction object, and its definition is specified in A rt. 3 points 5 of the Construction L aw Act of July 7, 1994 (J ournal of Laws of 2010, No. 243, item 1623, as amended). Hence, in the identification of loads on the structure of a mobile stage, one should also take into account the information contained in the set of standards defining the principles of designing and constructing structures known as the Eurocode.

\section{Load sharing of the hybrid multimedia mobile scene}

Due to the way of impact, the loads of mobile scenes can be classified as shown in Figure 2. The structure of the mobile stage is shaped in such a way that it can be easily transported. Due to the possibility of the mobile stage being moved, there are dynamic loads affecting the structure. With this type of load, the fatigue strength of the material becomes extremely important.

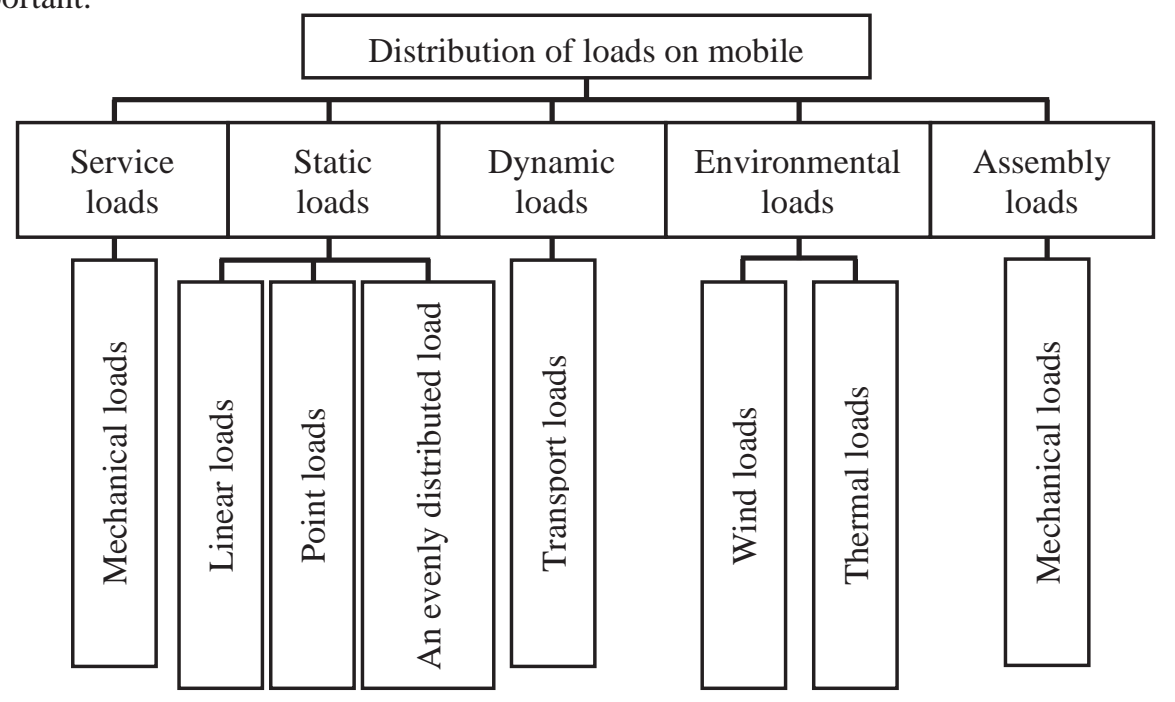

Fig. 2. Distribution of loads affecting mobile scenes.

The nature, intensity, value and frequency of the individual loads are very complex in this type of structure. A s a rule, static loads act in harmony with the forces of gravity, while dynamic loads may have components originating, for example, from the force of acceleration or braking. All types of loads require a thorough analysis before starting the basic theoretical or simulation calculations of individual structural elements of the mobile scene.

\section{Identification of loads on the hybrid multimedia mobile stage}

\subsection{Service and assembly loads}

Service and assembly loads are the basic group of impacts to which the mobile stage is exposed. The operation of this type of structure means not only the ability to move over Iong distances. In this case, you should also take into account the frequency with which the 
stage will be unfolded and folded. A very short time of unfolding and assembling a scene translates into a much greater frequency of its operation, which in turn may contribute to a much faster wear process of its individual structural elements. The process of folding and unfolding the mobile stage is usually based on hydraulic cylinders, therefore the assumed speed at which the structure is unfolded means that the loads associated with this process will be mainly static. It is also known that there are few structural elements in the construction of a mobile stage that require the operator to properly position and assemble it. In this case, the assembly load is understood as all kinds of attempts to tighten or unscrew the assembly screws.

\subsection{Static loads}

The identification of static loads affecting the structure of the mobile scene can be divided into three groups. The first group of loads, in a sense, consists of the imposed loads of the scene, including load resulting from the number of people who can stay on the unfolded platform at the same time [1]. This type of interaction should be treated as a point load, because a given place of the stage platform may contain mass of various values. In this case, the maximum number of people in the preliminary project assumptions is 60 people. A ssuming approx. $75 \mathrm{~kg} /$ person, we obtain a vertical load of $4500 \mathrm{~kg}$, ie approx. $44145 \mathrm{~N}$. However, this type of assumption is problematic to interpret in the case of any strength analyzes. This difficulty is due to the fact that the vertical load is not related to the surface it is supposed to act on. Constructors of small and medium-sized mobile stages (up to approx. $80 \mathrm{~m}^{2}$ ) assume the form of 4 persons $/ \mathrm{m}^{2}$. Referring this assumption to the concept of the project being implemented with a mobile stage, the stage platform of which is to constitute $120 \mathrm{~m} 2$ of usable space, it can be concluded that it is an assumption with a very high safety factor. The assumption that on each square meter the number of four people is allowed, for this accident, the design of the platform structure is designed, which can be influenced by a load of up to 480 people. A ssuming approx. $75 \mathrm{~kg} /$ person, this gives a vertical load of $36,000 \mathrm{~kg}$, that is approx. $353,160 \mathrm{~N}$. This solution has the most important advantageous value, which is safety, but there is a high risk of unnecessary oversizing of the structure.

The number of people on the stage is not the only load affecting it at that time. It should also be borne in mind that all stage groups have their props, equipment and many things necessary to perform the performance. Therefore, an appropriate value should be added to the above-estimated minimum value of this type of load affecting the stage of the mobile stage, as well as the own weight of the entire stage. This type of load will not be regarded as a concentrated load but rather as a continuous load evenly or freely distributed over the entire surface of the stage. Although the assumption of $200 \mathrm{~kg} / \mathrm{m}^{2}$ is more commonly used in practice [1]. Taking this value into account, in relation to the assumed area of the mobile stage of $120 \mathrm{~m}^{2}$, we obtain $24,000 \mathrm{~kg}$ of additional load, that is approx. $235440 \mathrm{~N}$. Summing up the presented loads, we obtain $60,000 \mathrm{~kg}$ of load acting on the stage platform (approx. $588600 \mathrm{~N}$ ). In addition to the presented value of the hypothetical load, it is also important in this case to take into account the own weight of the total structure of the platform.

Due to the possibility of leveling the hybrid multimedia mobile stage, it is also necessary to take into account the permissible load value in this group of loads, distributed on the hydraulically controlled leveling feet. The permissible load value of about $18,000 \mathrm{~kg}$ should be spread over the number of leveling feet of the mobile stage. This type of load is concentrated vertically. It should also be noted that the leveling feet, as the name suggests, are only intended to evenly level the stage platform and the entire mobile stage, and not to carry the total weight of the hybrid multimedia mobile stage. A ssuming the presence of 6 leveling feet in this situation, we obtain the distribution of the total load (approx. 60,000 $\mathrm{kg}$ ) of approx. $10,000 \mathrm{~kg}$ per leveling foot, which is in line with the preliminary 
assumptions of the mobile stage design assuming the permissible value of $18,000 \mathrm{~kg}$ per foot.

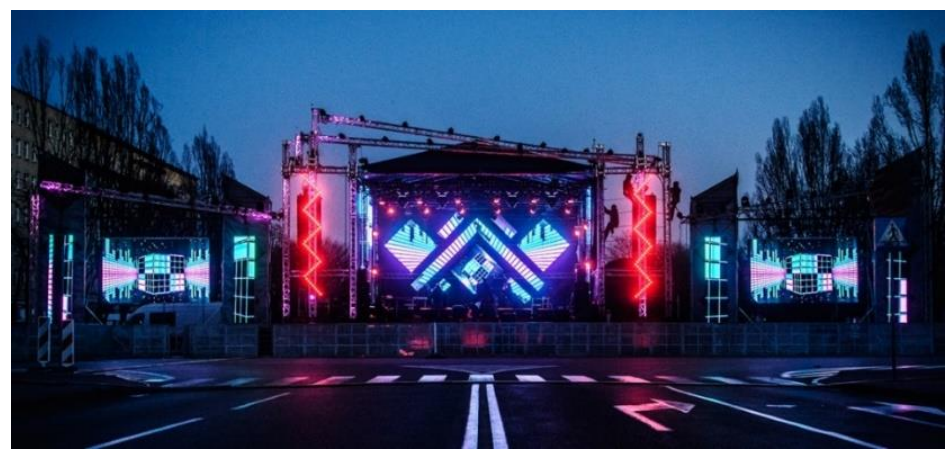

Fig. 3. Lighting and LED screens for mobile scenes.

One of the most important effects from the viewer@ point of view, in addition to sound effects, is the use of various lighting compositions and visual effects presented on LED screens in mobile scenes (Fig. 3). In most cases, the amount of lighting and sound installed is a serious challenge for the roof structure of mobile stages. The $50 \mathrm{~m}^{2} \mathrm{LED}$ screen itself, in accordance with the project assumptions, is associated with a load of $1,300 \mathrm{~kg}$ on the roof structure of the mobile stage. This load should also include a steel and aluminum frame (approx. $300 \mathrm{~kg}$ ) that allows the LED screen to be attached to the roof structure. As a result, when the LED screen is only suspended, the roof structure is subjected to a load of approx. $1500 \mathrm{~kg}$, i.e. approx. $14715 \mathrm{~N}$. A dditionally, it is assumed that four lines of lighting are to be suspended along a length of approx. $10 \mathrm{~m}$. A single line is a load for the roof structure of the mobile stage at the level of approx. $300 \mathrm{~kg}$, consequently adds an additional load of $1,200 \mathrm{~kg}$ (approx. 11,772 N). The result of this lighting arrangement and other visual effects is a total load of $2,700 \mathrm{~kg}(26,487 \mathrm{~N})$. The sound effects in the designed mobile stage are due to the appropriately placed sound system, which, in accordance with the laws of acoustics, is suspended from the side rails of the roof structure at the front of the mobile stage. In principle, these are two sets, one per side. The total weight of one set is approximately $1200 \mathrm{~kg}$. Thus, on each side, the load directed vertically downwards of the roof structure is approx. 23,544 N. Summing up all the above-mentioned possible operational loads of the roof structure, we finally obtain a mass effect of $5100 \mathrm{~kg}$, distributed unevenly in relation to the center of gravity of the entire structure of the mobile stage. It is this uneven distribution of this mass that constitutes an extraordinary challenge for the constructor, whose task is to properly balance this unevenness, thus ensuring the appropriate level of security of the mobile stage. One of the most important considerations at this stage will be the proper selection of the pillars of the mobile stage, on which both panels of the roof structure are based. It is this element that will also indirectly carry the loads resulting from the suspended lighting and sound system. It should also be noted that the other end of each of the four pillars included in the mobile stage structure is based on a stage platform. Therefore, this weight will also be indirectly transferred to the stage platform with a linear load, while the estimation of the impact of this effect on the strength of the platform can be known only on the basis of the analysis of the virtual FEM model.

\subsection{Environmental loads}

Equally important loads affecting the mobile scene will be the impact of, among others phenomena related to wind, snow or temperatures (so-called environmental loads) [2,3]. A significant difficulty in the case of this type of load is the wide variety of the degree of influence of a given phenomenon on the structure of the mobile stage, which depends on the location in which the structure is at a given moment. For example, the fluctuation of the 
environmental phenomenon in the form of wind for Poland is divided into three zones. In each of the three zones listed in PN-EN 1991-1-4 for Poland, different values of the base wind speed and wind speed pressure are presented. It follows that every other country will have a different division into zones, which probably have different wind speed and pressure values than in Poland. This is an extremely problematic situation in the case of mobile scenes, because they are constructed in such a way that they can be used in a variety of locations. There are no clear limitations in the project assumptions as to the area of use of the hybrid multimedia mobile scene. Therefore, it is necessary to assume in this case every possibility of the impact of environmental burdens that occurs at least in Europe. B ased on the above analysis, the impacts that should be given special attention are presented below.

Wind or gusts of wind are one of the first environmental loads that will affect the construction of the mobile stage. The PN -EN 1991-1-4 standard allows for the analysis of many types of structures. A mong other things, it enables the analysis of the wind impact on closed or open structures. Examples of closed structures are all kinds of houses with walls and a roof, while the simplest example of an open structure are sheds, which only consist of a roof, and do not have clear limitations in the form of walls. Nevertheless, in the case of shelters, the limitations for the wind will be any objects currently under the shelter (Fig. 4) [4].
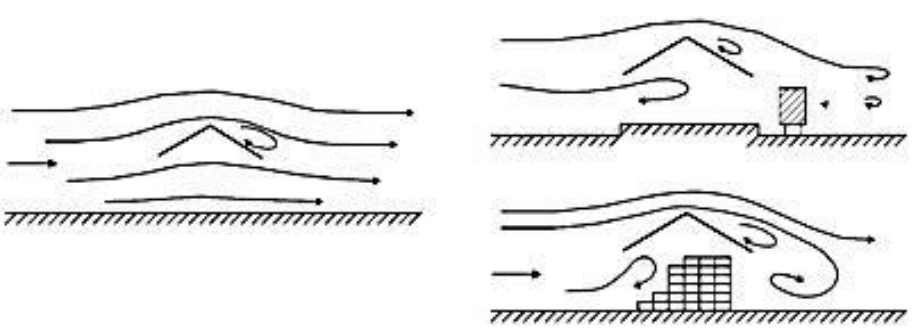

Fig. 4. A ir flow around the sheds [4].

In this case, the mobile stage is not a simple object, because it can be completely open, like a shed, and partially closed by covering selected sides of the mobile stage with e.g. a tarpaulin. Therefore, the analysis of the wind impact on the construction of the mobile stage should be considered for at least these two cases. In addition, wind loads show all signs of variability over time. This means that this type of load may be static or, in some cases, even dynamic. The action of the wind manifests itself directly as the pressure on the outer surfaces of the structure and, due to the permeability of the outer walls, as the pressure on the inner surfaces. The pressure exerted on the surfaces of the structure or its individual shielding elements causes forces perpendicular to them. In addition, when large areas of the structure are windblown by the wind, frictional forces acting tangentially to the surface also develop, which can be significant on the fatigue strength of the structure. The degree of wind impact, in this case, depends on the location and topography $[5,6]$.

Due to the fact that the structure of the hybrid multimedia mobile stage is intended for year-round use, the possibility of snow load on the roof structure should also be taken into account. Snow load should be divided into two basic groups: uniform and uneven snow load on the roof. Hence, it is assumed that the nature of this type of load is continuous, with even or arbitrary distribution. It should also be assumed that this load acts vertically in the area of the roof projection onto the horizontal plane. The method of analyzing the impact of snow on the structure is presented in the PN -EN 1991-1-3 standard.

Temperature changes may be an equally important load affecting the structure of the hybrid multimedia mobile stage. The minimum operational use of the mobile stage is determined for the area of the European continent, where there is a very wide distribution of occurring temperatures. Daily and seasonal changes in air temperature, solar radiation, 
radiation etc. cause changes in the temperature distribution in individual elements of the structure. The deformations and the resulting stresses depend on the geometry and boundary conditions of the analyzed element and on the physical properties of the materials used. In particular, when materials with different thermal expansion coefficients were used, creating a composite structure which in fact is, among others, hybrid multimedia mobile scene. The wider impact of this type of loads is presented in the PN -EN 1991-1-5 standard.

The third group of loads comes down to the total own weight of the mobile scene. In this dimension, several basic conditions have to be met, including, inter alia, the condition of the allowable ground pressure transmitted by the chassis of the semi-trailer. In accordance with the applicable road traffic law, the load resulting from the total own weight of the hybrid multimedia mobile stage may not exceed $44,000 \mathrm{~kg}$, ie $431640 \mathrm{~N}$. This weight should be distributed on each axle of the designed semi-trailer. This type of load will be treated as a concentrated load located in the places of wheel contact with the ground. The total value of the specific weight of the mobile stage will be comprised of all types of loads acting on the stage, not just the self-weight of individual structural el ements. Hence, the value of the permissible pressure of 44 tons should be reduced by the loads resulting from the number of people and additional equipment carried on the stage platform, as well as the load resulting from, for example, snow retention on the roof surface. Detailed data related to self-weight loads are presented in PN -EN 1991-1-1.

Table 1 presents the classification of loads affecting the structure of a hybrid multimedia mobile stage based on the PN-EN 1991-1-6 standard. The list also includes other loads not described in more detail in the report bel ow [7].

Table 1. Classification of loads affecting the hybrid multimedia mobile scene.

\begin{tabular}{|c|c|c|c|c|}
\hline \multirow[b]{2}{*}{ Load } & \multicolumn{4}{|c|}{ Classification } \\
\hline & $\begin{array}{l}\text { Volatility } \\
\text { over time }\end{array}$ & Origin & Variation in space & $\begin{array}{l}\text { Character } \\
\text { (static/ } \\
\text { dynamic) }\end{array}$ \\
\hline Own weight & Constant & Direct & $\begin{array}{l}\text { Placed with } \\
\text { tolerance / Not } \\
\text { placed }\end{array}$ & Static \\
\hline $\begin{array}{c}\text { Initial } \\
\text { deformation }\end{array}$ & $\begin{array}{l}\text { Constants/ } \\
\text { V ariables }\end{array}$ & Indirect & Not Placed & Static \\
\hline Compression & $\begin{array}{l}\text { Constants/ } \\
\text { V ariables }\end{array}$ & Direct & Placed & Static \\
\hline Temperature & Variables & Indirect & Not Placed & Static \\
\hline W ind actions & $\begin{array}{c}\text { Variables/ } \\
\text { Unique }\end{array}$ & Direct & Placed / N ot Placed & $\begin{array}{c}\text { Staticl } \\
\text { Dynamic }\end{array}$ \\
\hline Snow load & $\begin{array}{c}\text { Variables/ } \\
\text { Unique }\end{array}$ & Direct & Placed / N ot Placed & $\begin{array}{c}\text { Staticl } \\
\text { Dynamic }\end{array}$ \\
\hline $\begin{array}{c}\text { A tmospheric ice } \\
\text { loads }\end{array}$ & V ariables & Direct & Not Placed & $\begin{array}{c}\text { Staticl } \\
\text { Dynamic }\end{array}$ \\
\hline & \multicolumn{4}{|c|}{ Classification of executive loads } \\
\hline $\begin{array}{c}\text { Staff and } \\
\text { handheld tools }\end{array}$ & V ariables & Direct & Placed & Static \\
\hline $\begin{array}{c}\text { Storage of } \\
\text { portable items }\end{array}$ & V ariables & Direct & Not Placed & $\begin{array}{c}\text { Staticl } \\
\text { Dynamic }\end{array}$ \\
\hline $\begin{array}{c}\text { Non-permanent } \\
\text { devices }\end{array}$ & V ariables & Direct & Placed / N ot Placed & $\begin{array}{c}\text { Staticl } \\
\text { Dynamic }\end{array}$ \\
\hline $\begin{array}{l}\text { Portable heavy } \\
\text { machinery and } \\
\text { equipment }\end{array}$ & V ariables & Direct & Not Placed & $\begin{array}{c}\text { Static/ } \\
\text { Dynamic }\end{array}$ \\
\hline
\end{tabular}




\begin{tabular}{|c|c|c|c|c|}
\hline $\begin{array}{c}\text { Consumption of } \\
\text { used materials }\end{array}$ & V ariables & Direct & Not Placed & $\begin{array}{c}\text { Static/ } \\
\text { Dynamic }\end{array}$ \\
\hline $\begin{array}{c}\text { L oads from } \\
\text { parts of } \\
\text { structures in } \\
\text { transition }\end{array}$ & V ariables & Direct & Not Placed & Static \\
\hline
\end{tabular}

\subsection{Dynamic loads}

Due to the mobility of the analyzed hybrid multimedia scene, it is also necessary to identify the loads affecting both structural and non-structural elements during transport. The first concept of the construction of a mobile scene in a complex form is shown in Figure 5.

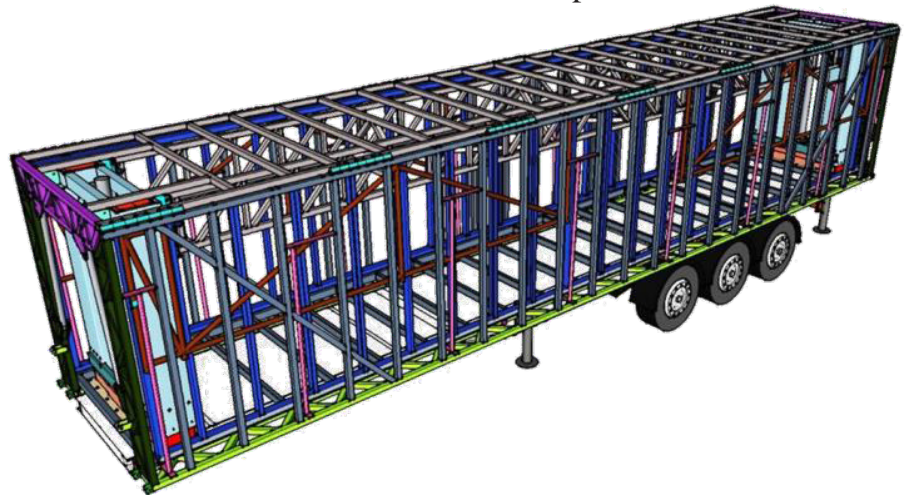

Fig. 5. Hybrid M ultimedia M obile Stage - I design concept - in a folded state.

During transport, numerous dynamic effects may occur, such as acceleration, braking, etc., and the accompanying inertial forces. More extensive information on this area is contained in the EN 1991-1-1 standard, while Figure 6 shows a schematic planar system of forces acting on a semi-trailer moving with accelerated uphill motion $[8,9,10]$. It is also the most general case of loading all resistance to motion with forces.

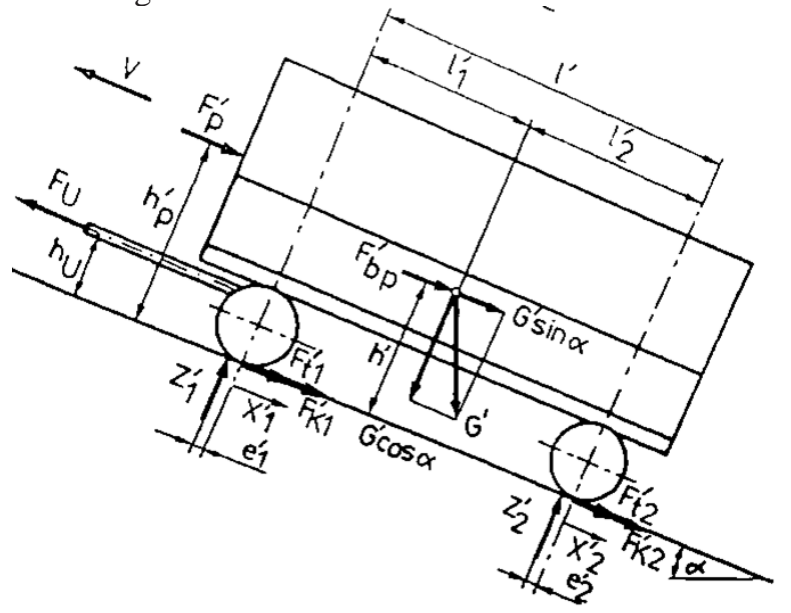

Fig. 6. The flat system of forces acting on the trailer during accelerated uphill motion [8].

The air resistance vector $F_{p}^{\prime}$ is applied to the front face of the trailer at a distance $h_{p}^{\prime}$ from the surface. Due to the movement of the semi-trailer in the gaseous medium of the surrounding air, it is under the influence of aerodynamic force. This force is divided into two components: longitudinal, parallel to the symmetry axis of the semi-trailer, turning 
opposite to the direction of traffic, transverse, parallel to the road surface, also called lateral pressure, and perpendicular to the road surface, called the lifting force. The transverse component occurs when the wind direction is not parallel to the direction of the trailer movement $[11,12]$. The lifting force, on the other hand, changes the normal load of the axle. The directions of action of the components of the aerodynamic force do not pass through the center of gravity, but the result is the occurrence of additional aerodynamic moments. In a system of coupled vehicles, the traction resistance $F_{u}$ is the internal force. On the other hand, when considering the system of forces acting on these vehicles separately, the traction resistance is an additional resistance to the car@ movement and, at the same time, the force that forces the semi-trailer to move $[13,14]$. Figure 6 shows the horizontal location of the trailer drawbar, thus reducing the occurrence of the normal force component causing the change of the normal axle load. All wheels of the semi-trailer are wheels that are not driven by the prime mover and are called rolled wheels. In the case of turned wheels, the tangential reactions of the surface are directed against the direction of the traffic. In the figure above, these reactions are marked with symbols $X_{1}^{\prime}$ and $X_{2}^{\prime}$. In the adopted system of forces of the semi-trailer, the rolling resistance on individual axles was also distinguished [15]. The symbols that define this parameter are $F_{t 1}^{\prime}$ and $F_{t 2}^{\prime}$. However, they can be obtained from the following dependencies: $F_{t 1}^{\prime}=Z_{1}^{\prime} * f_{t}^{\prime}$ and $F_{t 2}^{\prime}=Z_{2}^{\prime} * f_{t}^{\prime}$. The parameter $f_{t}^{\prime}$ is the rolling resistance coefficient, which depends on many different factors, in particular, such as: the type and structure of the tire, tire pressure, speed of the towing vehicle, but also the quality and condition of the surface. The parameter $Z^{\prime}$ is a normal reaction which depends on the car $\odot$ gravity and road gradient. In the analyzed case, the wheel inertia force $\left(F_{k 1}^{\prime}, F_{k 2}^{\prime}\right)$ in rotational motion should also be taken into account. This force for non-driven wheels is determined by dividing by the dynamic radius the moment of inertia resistance of the wheel $M_{b k}$.

\section{Conclusion}

The hybrid multimedia mobile stage is a very complex structure that is subjected to various loads, both static and dynamic. The identification of the influenced loads is additionally complicated by the large area of use of the mobile stage and the fact that it is subjected to other loads in a distributed and complex state. In each of the analyzed cases, one should be guided mainly by the safety index in order to minimize the risk of undesirable situations in the form of, for example, critical damage to the structure of the mobile stage, which is a serious risk of losing the life and health of users and people in its immediate vicinity. From the diagnostic point of view, understanding the correct functioning of the facility as well as collecting and preliminary analysis of information related to the various range of loads affecting it is the basis for the development and testing of the effectiveness of diagnostic systems.

This paper has been achieved under the research project "Hybrid multimedia mobile scenes are a chance for decisive innovation" No. POIR .04.01.04-00-0045/17-00.

\section{References}

1. P. Hajduk, Obciążenia podłóg przemysłowych, Przegląd Budowlany, Vol. 7-8, pp. 6776 (2017)

2. A. Biegus, Nadchodzi czas Eurokodów, Wiadomości Projektanta Budownictwa, Vol. 3, pp. 27-31 (2011)

3. A. Kozłowski, Konstrukcje stalowe - Przykłady obliczeń według PN-EN 1993-1, Copyright Politechnika Rzeszowska, Rzeszów (2015)

4. PN-EN 1991-1-4:2008, Eurokod 1, Oddziaływania na konstrukcję, Część 1-4: Oddziaływania ogólne - Oddziaływania wiatru 
5. J. A. Żurański, M. Gaczek, Obciążenie wiatrem budynków w ujęciu normy PN-EN 1991-1-4:2008, Inżynieria i Budownictwo, No 9, pp. 495-501 (2010)

6. T. Lipecki, Oddziaływanie wiatru na budynki wysokie w świetle badań własnych i ujęć normowych, Budownictwo i Architektura, 12 (2), pp. 143-150 (2013)

7. T. Lipecki, Struktura wiatru i badania modelowe obciążenia wiatrem budowli prostopadłościennych, Copyright Politechnika Lubelska, L ublin (2015)

8. B. Landowski, Ł. Muślewski, Decision model of an operation and maintenance process of city buses, 58th International Conference of M achine Design Departments ICM D 2017, Czech University of L ife Sciences, Czech Republic, pp. 188-193, (2017)

9. W. Siłka, Teoria ruchu samochodu (W NT, W arszawa, 2002)

10. Z. Lozia, Vehicle dynamics simulation models of two emergency vehicles, M echanics, Technical Transactions, V ol. 109, pp. 19-34 (2012)

11. T. D. Gillespie, Fundamentals of vehicle dynamics, SA E, Inc. Warrendale (1994)

12. M. Łukasiewicz, M. Liss, N. Dluhunovych, Analysis of vibrodiagnostics methods in the technical state study of designed multimedia mobile scenes, 18th International Conference Diagnostics of Machines and Vehicles, MATEC Web of Conferences, Vol. 302 (2019)

13. Żółtowski M., Jeleniewicz K.: The use of modal analysis to examine the lattice structure. Przegląd Naukowy Inżynieria i Kształtowanie Środowiska, Vol. 28 (3), No 85, pp.332-344 (2019)

14. P. Strzelecki, A. M azurkiewicz, J. Musiał, T. Tomaszewski, M. Słomion, Fatigue Life for Different Stress Concentration Factors for Stainless Steel 1.4301, M aterials, 12, 3677 (2019)

15. Ł. Muślewski, M. Pająk, A. Grządziela, J. Musiał, A nalysis of vibration time histories in the time domain for propulsion systems of minesweepers, Journal of V ibroengineering, V ol. 17, Issue 3, pp. 1309-1316 (2015) 